\title{
Reducción de proteínas y glucosa por reacción de Maillard en leche con lactosa hidrolisada
}

\section{Protein and glucose reduction by Maillard reaction in milk with hydrolyzed lactose}

\section{RESUMEN}

Se evaluó el efecto de la temperatura sobre la desnaturalización de proteínas y la reacción de Maillard en leche entera y descremada con lactosa hidrolizada. Las leches hidrolizadas se trataron térmicamente a 100, 110, 120 y $130{ }^{\circ} \mathrm{C}$ durante un período de 1 hora y se midió la concentración de glucosa, el grado de pardeamiento y la desnaturalización de proteínas. El grado de dorado en la leche entera varió de $14.4\left(100{ }^{\circ} \mathrm{C}\right)$ a $42.6\left(130^{\circ} \mathrm{C}\right)$. Para la leche descremada fue de 20.2 (100 ${ }^{\circ} \mathrm{C}$ ) a 38.0 $\left(130^{\circ} \mathrm{C}\right)$. La concentración de glucosa en leche entera $(47 \%$ p/v) y en leche descremada (41\% p/v) después del tratamiento térmico $\left(130{ }^{\circ} \mathrm{C}\right)$ mostró una reducción significativa en relación con el control $\left(25^{\circ} \mathrm{C}\right)$. El efecto de la temperatura en la desnaturalización de proteínas en leche entera y descremada en relación con el control (25 ${ }^{\circ} \mathrm{C}$ ) fue del $100 \%$. La leche tratada térmicamente con lactosa hidrolizada promovió la desnaturalización de proteínas con un aumento del pardeamiento característico de la reacción de Maillard, lo que afectó la calidad nutricional. Palabras clave: Beta-galactosidasa; Desnaturalización proteica; Hidrólisis enzimática; Tratamiento térmico.

\footnotetext{
ABSTRACT

The effect of temperature in protein denaturation and Maillard reaction in whole and skim milk with hydrolyzed lactose was evaluated. Hydrolyzed milk was thermally treated at 100, 110, 120 and $130{ }^{\circ} \mathrm{C}$ over a period of 1 hour and glucose concentration, browning degree and protein denaturation were measured. The browning degree in whole milk varied from 14.42 (100 ${ }^{\circ} \mathrm{C}$ ) to 42.63 $\left(130{ }^{\circ} \mathrm{C}\right.$ ) and $20.21\left(100{ }^{\circ} \mathrm{C}\right)$ to $38.03\left(130{ }^{\circ} \mathrm{C}\right)$ in skim milk. Glucose concentration in whole milk $(47 \%-w / v)$ and skim milk (41\% - w/v) after heat treatment $\left(130{ }^{\circ} \mathrm{C}\right)$ showed a significant reduction in relation to the control $\left(25{ }^{\circ} \mathrm{C}\right)$. The temperature effect in protein denaturation in whole and skim milk in relation to the control $\left(25^{\circ} \mathrm{C}\right)$ was $100 \%$. Thermally treated milk with hydrolyzed lactose promoted protein denaturation with increasing browning characteristic of the Maillard reaction, thus affecting the nutritional quality.
}

Hélio Hiroshi $S^{1}$, Samuel Guemra ${ }^{1}$, Alessandra Bosso ${ }^{1}$, Érika de Pádua $A^{1}$, Luiz Rodrigo Ito $M^{1 *}$.

1. Universidad Pitágoras Unopar. Programa de posgrado en Leche y Tecnología Láctea. Universidad Pitágoras Unopar, Londrina, Brasil.

*Dirigir correspondencia a: Luiz Rodrigo Ito Morioka. Universidad Pitágoras Unopar.

Programa de posgrado en Leche y Tecnología Láctea. Calle Marsella, 591. Londrina, Paraná, Brasil. CEP: 86041-140. Teléfono +55 (43)33717723. Email: luiz.morioka@kroton.com.br

Este trabajo fue recibido el 18 de julio de 2018. Aceptado con modificaciones: 30 de abril de 2019. Aceptado para ser publicado: 13 de agosto de 2019.

Keywords: Beta-galactosidase; Enzymatic hydrolysis; Heat treatment; Protein denaturation.

\section{INTRODUCCIÓN}

La leche es considerada un alimento rico en nutrientes y de fundamental importancia para el ser humano, ya que en su constitución hay agua, proteínas, carbohidratos, grasas, vitaminas, minerales y otros ${ }^{1,2}$. La lactosa es el carbohidrato que se encuentra en la leche y cuando se ingiere, este azúcar se hidroliza en sus monómeros, glucosa y galactosa, a través de la acción de la enzima beta-galactosidasa, también conocida como lactasa ${ }^{3,4}$.

La incapacidad del cuerpo para absorber la lactosa presente en la leche y sus derivados se caracteriza como 
intolerancia a la lactosa. La intolerancia a la lactosa es una deficiencia que afecta a alrededor del $70 \%$ de la población mundial7. En América del Sur, más del 50\% de la población presenta esta deficiencia, ya que en Brasil este porcentaje puede alcanzar el $44 \%{ }^{8}$. Por lo tanto, para estos grupos de personas, el desarrollo y la producción de leche baja en lactosa genera un interés considerable en la industria láctea. La hidrólisis de la lactosa láctea genera dos monómeros, galactosa y glucosa, por lo que, dependiendo del tratamiento térmico aplicado, la reacción de Maillard dará como resultado un menor valor nutricional y una calidad sensorial de la leche ${ }^{9,10}$. La reacción de Maillard es una reacción química entre un aminoácido y un azúcar reductor, que generalmente requiere la adición de calor. Al igual que la caramelización, es una forma de pardeamiento no enzimático. Por lo tanto, el efecto de la temperatura en la desnaturalización de la proteína y la reacción de Maillard en la leche UHT (Ultra High Temperature) con bajo contenido de lactosa es necesario para este tipo de producto alimenticio. Los datos de la Federación Internacional de Lechería mostraron que el consumo de leche hidrolizada aumentó en un $7,6 \%$ en Italia en 2014. En Brasil, en 2015 este aumento fue de un $5,9 \%$ en el desarrollo de alimentos y bebidas que aportó información en el envase que indicaba una reducción en la cantidad o ausencia de lactosa ${ }^{11}$.

Técnicamente, se debe prestar atención al control del grado de hidrólisis de la lactosa por la enzima beta-galactosidasa ${ }^{12}$. Dependiendo de las condiciones de procesamiento, algunos cambios se vuelven irreversibles en la composición de la leche, como la pérdida de vitaminas, el aumento de la viscosidad y el sabor dulce del producto, comenzando el proceso oxidativo que deteriora la calidad de la leche, la isomerización de la lactosa, la alteración del color y la desnaturalización de proteínas por la intensificación de la reacción de Maillard 13,14,15,16,17. Los dos últimos cambios están directamente relacionados con la composición del carbohidrato alterado en la leche hidrolizada, con la formación de glucosa y galactosa además de la mayor reactividad con los grupos amina (lisina unida a la proteína primaria y otros terminales $\mathrm{NH})^{18,19,20}$. Teniendo como resultado la reducción de la digestibilidad y la inhibición de algunas enzimas que pueden resultar en la pérdida del valor nutricional de los alimentos ${ }^{21,22}$.

El grado de evaluación del daño causado por el tratamiento térmico en el procesamiento de la leche debido a la reacción de Maillard puede verificarse analizando la evaluación del grado de pardeamiento de la leche y la evaluación del grado de desnaturalización de la proteína de la leche ${ }^{23,24}$. Demostrando así la baja calidad del producto final. El objetivo de este trabajo fue verificar el efecto de la temperatura en la desnaturalización de las proteínas, el cambio de color y el contenido de glucosa en la leche entera UHT y en la leche descremada con lactosa hidrolizada. El oscurecimiento y la desnaturalización de las proteínas de la leche en relación con las condiciones de calentamiento se establecieron mediante ecuaciones de regresión.

\section{MATERIALES Y MÉTODOS \\ Muestras y tratamientos}

Para realizar los experimentos, se obtuvo leche UHT entera y descremada del mercado local (Brasil). La composición química de la leche entera reportada por el fabricante fue de $33 \mathrm{~g} / \mathrm{L}$ de proteína, $34 \mathrm{~g} / \mathrm{L}$ de grasa, 53 $\mathrm{g} / \mathrm{L}$ de azúcares, $0,55 \mathrm{~g} / \mathrm{L}$ de sodio y de 1,2 g/L de calcio. Mientras que para la leche descremada, la composición fue de $34 \mathrm{~g} / \mathrm{L}$ de proteína, $1 \mathrm{~g} / \mathrm{L}$ de grasa, $53 \mathrm{~g} / \mathrm{L}$ de azúcares, $0,55 \mathrm{~g} / \mathrm{L}$ de sodio y $1,2 \mathrm{~g} / \mathrm{L}$ de calcio.

Las diferentes leches se trataron con beta-galactosidasa comercial (Maxilact ${ }^{\circledR}$-L500) a una concentración de 1 $\mu \mathrm{L} / \mathrm{mL}(\mathrm{v} / \mathrm{v})$ durante 5 horas a $37^{\circ} \mathrm{C}$. De acuerdo con el fabricante este tiempo de temperatura son sujetas a la hidrólisis de la lactosa. En estas condiciones el contenido de lactosa de ambas leches fue inferior al 10\% (v/v) (datos no mostrados). Luego se inactivaron en un baño de agua a $95^{\circ} \mathrm{C}$ durante 5 minutos. Las muestras de leche hidrolizada entera y descremada se fraccionaron en cinco grupos experimentales, uno de los cuales se mantuvo a $25^{\circ} \mathrm{C}$ (control). Los otros cuatro grupos se trataron térmicamente a $100,110,120$ y $130{ }^{\circ} \mathrm{C}$ realizado en una autoclave a 1 atm por 20 minutos, como se muestra en la figura 1. Las muestras tratadas térmicamente y el control se analizaron por triplicado para validar la reproducibilidad.

\section{Cuantificación de la glucosa}

Los niveles de glucosa en la leche se determinaron utilizando el kit enzimático colorimétrico de glucosa oxidasa (Laborclin ${ }^{\circledR}$, Brasil). Para realizar las pruebas, las muestras de leche se diluyeron 1:20 con agua ultrapura. Los procedimientos de análisis y el cálculo de las concentraciones siguieron estrictamente las recomendaciones del fabricante del kit.

\section{Evaluación de color}

El color de las muestras de leche entera y descremada hidrolizada se determinó por reflectancia utilizando el colorímetro Minolta CR-400 (Konica Minolta Sensing, Inc., Osaka, Japón), con iluminante D65 debidamente calibrado. Las muestras fueron analizadas a temperatura ambiente (25 ${ }^{\circ} \mathrm{C}$ ). Los valores de $\mathrm{L}^{*}$ (luminosidad), $\mathrm{a}^{*}$ (componente rojoverde) y $b^{*}$ (componente amarillo-azul) se expresaron en el sistema CIELab. Las diferencias de color totales $\left(\Delta \mathrm{Eab}^{*}\right)$ se calcularon de la siguiente manera:

\section{Fracciones proteicas}

La influencia del calentamiento en las proteínas de la leche tratadas térmicamente o no (control) se determinó mediante SDS-PAGE en un gel de separación al 12,5\% y un gel espaciador al $5 \%$, con algunas modificaciones menores ${ }^{25}$. Para las muestras de desnaturalización, se trataron $100 \mu \mathrm{L}$ de leche con $250 \mu \mathrm{L}$ de solución tampón (60 mg Tris, 800 $\mu \mathrm{L}$ de glicerol, $100 \mathrm{mg}$ de dodecilsulfato de sodio, $400 \mu \mathrm{L}$ de $\beta$-mercaptoetanol, $4 \mathrm{mg}$ de bromofenol azul y Qsp de $\mathrm{H}_{2} \mathrm{O}$ ultrapuro a $8 \mathrm{~mL}$ ) y se calentó en un baño de agua a $90{ }^{\circ} \mathrm{C}$ durante 5 min. Después de la desnaturalización 
de la proteína, se colocó una alícuota de $10 \mu \mathrm{L}$ de cada muestra diluida en los geles de SDS-PAGE en unidad de electroforesis vertical (Bio-Rad Laboratories). El gel se tiñó con la solución de Coomassie Blue R-250 al 0,23\% durante 90 minutos y se decoloró en la solución de metanol/ácido acético ( $5 \%$ de metanol, $7 \%$ de ácido acético).

\section{Análisis estadístico}

Todos los análisis se realizaron por triplicado. Los datos obtenidos fueron reportados como valores medios. Los análisis estadísticos se realizaron utilizando el programa estadístico BioEstat 5.3. Para los análisis de varianza se utilizó la prueba de Tukey como un procedimiento de comparaciones múltiples entre los tratamientos. Se definió un nivel $\mathrm{p}<0.05$ como de significancia estadística.

\section{RESULTADOS}

El efecto de las diferentes temperaturas en la concentración de glucosa y el análisis de color en la leche entera y la leche descremada se pueden observar en la figura 1. En las figuras $2 \mathrm{~A}$ y $2 \mathrm{~B}$ se muestra que la concentración de glucosa presentó una reducción significativa $(p<0.05)$ en los tratamientos térmicos probados en relación con el control a $25{ }^{\circ} \mathrm{C}(2.58 \mathrm{mg} / \mathrm{dL}$ en leche entera y $2.59 \mathrm{mg} / \mathrm{dL}$ en leche descremada. De acuerdo con los tratamientos térmicos a 100, 110, 120 y $130{ }^{\circ} \mathrm{C}$, la concentración de glucosa para la leche entera fue de 2.20, 1.88, 1.67 y 1.37 $\mathrm{mg} / \mathrm{dL}$, respectivamente, y $1.91,1.68,1.56$ y $1.52 \mathrm{mg} / \mathrm{dL}$, respectivamente, para la leche descremada. En la leche entera hidrolizada, el tratamiento térmico a $100{ }^{\circ} \mathrm{C}(2,20 \mathrm{mg} /$ $\mathrm{dL})$ y $110^{\circ} \mathrm{C}(1,88 \mathrm{mg} / \mathrm{dL})$, la concentración de glucosa no mostró diferencias significativas ( $p>0,05)$. Al igual que a 120 ${ }^{\circ} \mathrm{C}(1.67 \mathrm{mg} / \mathrm{dL})$ y $130{ }^{\circ} \mathrm{C}(1.37 \mathrm{mg} / \mathrm{dL})$ no hubo diferencias significativas ( $p>0.05)$. Sin embargo, la cantidad de glucosa en la leche entera tratada a $100{ }^{\circ} \mathrm{C}(2.20 \mathrm{mg} / \mathrm{dL})$ presentó una diferencia significativa $(p<0.05)$ en relación con los tratamientos con $120{ }^{\circ} \mathrm{C}(1.67 \mathrm{mg} / \mathrm{dL})$ y $130{ }^{\circ} \mathrm{C}(1,37 \mathrm{mg} /$ dL). En leche descremada hidrolizada, la concentración de glucosa osciló entre $1.91 \mathrm{mg} / \mathrm{dL}$ a $100{ }^{\circ} \mathrm{C}$ y $1.52 \mathrm{mg} / \mathrm{dL}$ a $130^{\circ} \mathrm{C}$. Los niveles de glucosa fueron similares ( $\left.p>0.05\right)$ cuando se trataron a $100{ }^{\circ} \mathrm{C}(1.91 \mathrm{mg} / \mathrm{dL})$ y $110{ }^{\circ} \mathrm{C}(1.68$ $\mathrm{mg} / \mathrm{dL})$. La leche tratada a $110^{\circ} \mathrm{C}(1.68 \mathrm{mg} / \mathrm{dL}), 120^{\circ} \mathrm{C}(1.56$ $\mathrm{mg} / \mathrm{dL})$ y $130^{\circ} \mathrm{C}(1.52 \mathrm{mg} / \mathrm{dL})$ no presentó diferencias en los niveles de glucosa ( $p>0.05)$. La leche tratada a $120^{\circ} \mathrm{C}$ y $130^{\circ} \mathrm{C}, 1.56$ y $1.52 \mathrm{mg} / \mathrm{dL}$, respectivamente, no mostró una diferencia significativa ( $p>0.05$ ) en la concentración de glucosa, sin embargo, la cantidad de glucosa en la leche tratada con $100{ }^{\circ} \mathrm{C}(1.91 \mathrm{mg} / \mathrm{dL})$ fue mayor $(\mathrm{p}<0.05)$ en los grupos tratados a $120^{\circ} \mathrm{C}(1.56 \mathrm{mg} / \mathrm{dL})$ y $130{ }^{\circ} \mathrm{C}(1.52 \mathrm{mg} /$ $\mathrm{dL}$ ). En las figuras $2 \mathrm{C}$ y $2 \mathrm{D}$, los resultados muestran que el grado de pardeamiento de las leches hidrolizadas varió debido a la temperatura $(\mathrm{p}<0.05)$. El grado de pardeamiento

\section{Leche entera}

\section{Leche descremada}

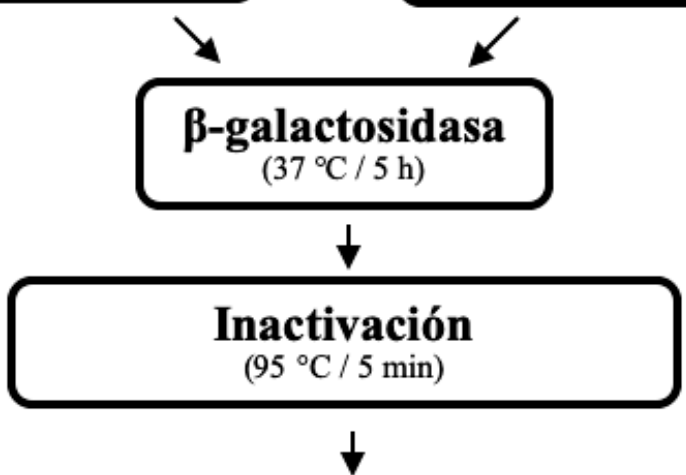

\section{Tratamiento térmico \\ $\left(100,110,120\right.$ e $\left.130^{\circ} \mathrm{C} / 1 \mathrm{~h}\right)$}

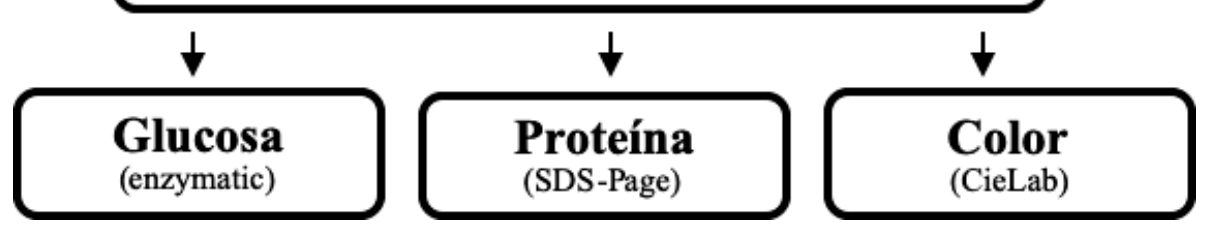

Figura 1: Diseño experimental para verificar el efecto del tratamiento térmico en leche hidrolizada. 


\section{Leche entera}

(A)

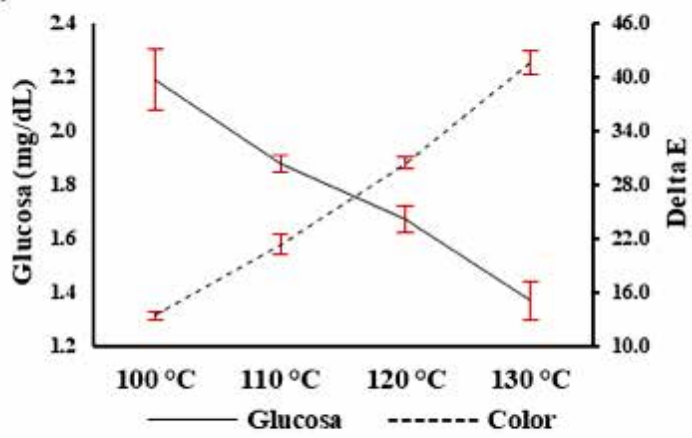

(C)

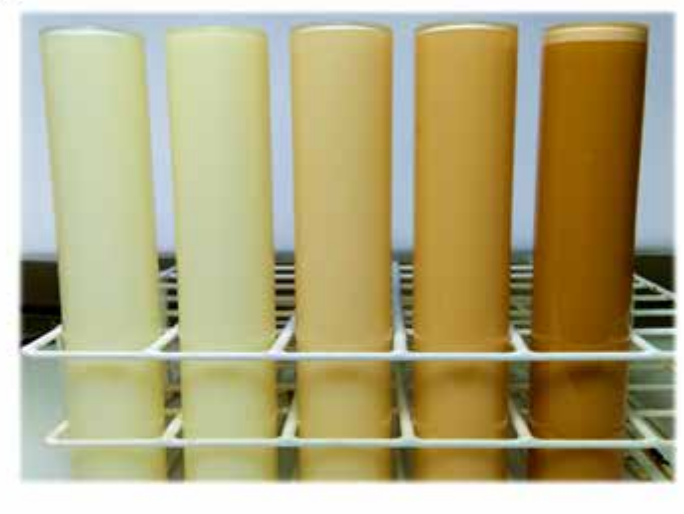

\section{Leche descremada}

(B)

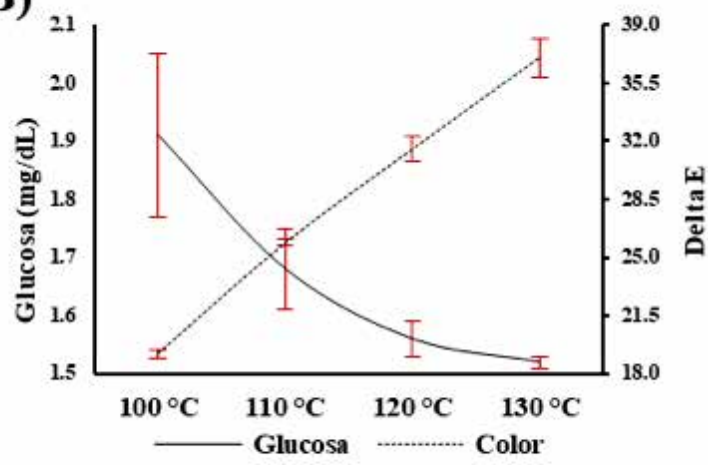

(D)

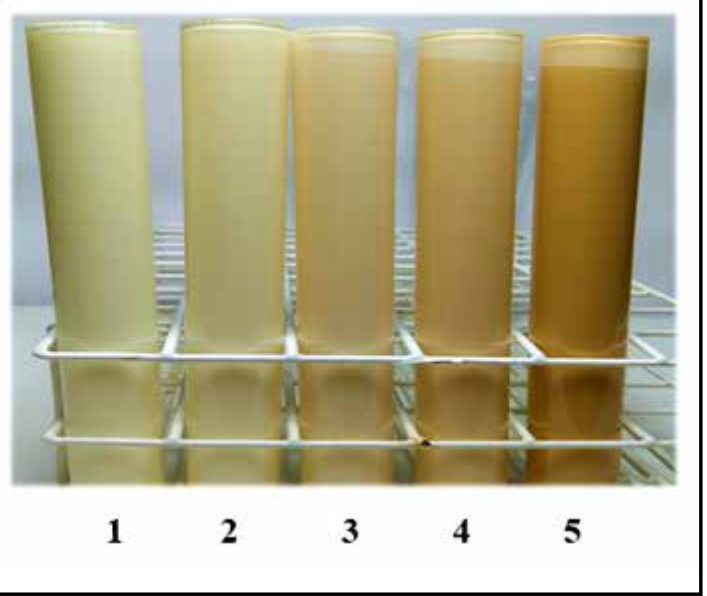

Figura 2: Concentración de glucosa y reacción de color en leche entera (A), concentración de glucosa y reacción de color en leche descreamada (B), desnaturalización de proteínas en leche entera $(C)$ y desnaturalización de proteínas en leche descremada (D). Línea $1: 25^{\circ} \mathrm{C}$ (control), líneas 2 a 5: $100{ }^{\circ} \mathrm{C}, 110^{\circ} \mathrm{C}, 120^{\circ} \mathrm{C}$ y $130{ }^{\circ} \mathrm{C}$.

(delta $\mathrm{E}$ ) en la leche entera fue de 14.4 a $100{ }^{\circ} \mathrm{C}, 22.4$ a 110 ${ }^{\circ} \mathrm{C}, 31.4$ a $120^{\circ} \mathrm{C}$ y 42.6 a $130{ }^{\circ} \mathrm{C}$. En leche descremada, el delta $\mathrm{E}$ fue de 20.2 a $100{ }^{\circ} \mathrm{C}, 26.9$ a $110{ }^{\circ} \mathrm{C}, 32.5$ a $120^{\circ} \mathrm{C}$ y 38.0 a $130{ }^{\circ} \mathrm{C}$. El delta $\mathrm{E}$ del control a $25^{\circ} \mathrm{C}$ para ambos tipos de leche hidrolizada fue igual a 1.0.

El grado de pardeamiento en el color de la leche hidrolizada entera y desnatada presentó una regresión exponencial con las diferentes temperaturas del tratamiento térmico. Para leche entera hidrolizada la regresión fue para concentración de glucosa y para dorar la leche. En leche descremada hidrolizada la regresión para concentración de glucosa fue y para dorar leche; donde $\mathrm{Y}$ representa la reducción de la concentración de glucosa $(\mathrm{mg} / \mathrm{dL})$ y el grado de pardeamiento en leche entera y descremada, ambas hidrolizadas respectivamente. No hay diferencia en el contenido del contenido de glucosa de la leche entera hidrolizada y la leche descremada hidrolizada.

El efecto de las diferentes temperaturas que influyen en el porcentaje de desnaturalización de las proteínas de la leche inicial se muestra en la figura 3. Se puede observar que la desnaturalización de las proteínas en la leche entera, (Figura 3A), mostró un aumento significativo $(\mathrm{p}<0.05)$ entre las temperaturas. Tratamientos a $100{ }^{\circ} \mathrm{C}(2.48 \%)$ y $130{ }^{\circ} \mathrm{C}$ $(0,01 \%)$. El porcentaje de desnaturalización de proteínas en relación con el control $\left(25^{\circ} \mathrm{C}\right)$ fue del $14,7 \%$ a $100^{\circ} \mathrm{C}$ y del $99,7 \%$ a $130^{\circ} \mathrm{C}$. Entre las temperaturas en $110^{\circ} \mathrm{C}(0,56 \%)$, $120^{\circ} \mathrm{C}(0,12 \%)$ y $130{ }^{\circ} \mathrm{C}(0,01 \%)$ la desnaturalización era gradual, presentando una diferencia significativa cuando se compara con el grupo de control a $25{ }^{\circ} \mathrm{C}(2,91 \%)$ y al tratamiento térmico de $100{ }^{\circ} \mathrm{C}(2,48 \%)$. En la leche descremada, la figura $3(\mathrm{~B})$, el tratamiento térmico a $100^{\circ} \mathrm{C}$ $(2,34 \%), 110{ }^{\circ} \mathrm{C}(0,70 \%), 120^{\circ} \mathrm{C}(0,28 \%)$ y $130{ }^{\circ} \mathrm{C}(0,10 \%)$ 
mostró un aumento significativo $(\mathrm{p}<0.05)$ en desnaturalización de la proteína, en comparación con el control $25^{\circ} \mathrm{C}(3,17$ el desnatada calefacción leche a $110^{\circ} \mathrm{C}, 120^{\circ} \mathrm{C}$ y $130{ }^{\circ} \mathrm{C}$ $(p<0,05)$ el aumento de la desnaturalización de proteínas durante el tratamiento a $100{ }^{\circ} \mathrm{C}$.

Las muestras de leche entera y descremada se sometieron a tratamiento térmico y el análisis del porcentaje de degradación de la proteína inicial se analizaron por la técnica de electroforesis en SDS-PAGE, como se muestra en la figura 3. La diferencia entre la leche hidrolizada sin tratar y tratados con calor confirmó que la Las proteínas tienen diferentes grados de desnaturalización bajo diferentes condiciones de tratamiento térmico. En toda la leche hidrolizada, a partir de $120^{\circ} \mathrm{C}$, se verifica el inicio de la formación del complejo entre las proteínas del suero y las caseínas, de modo que los enlaces disulfuro se rompen, causando una degradación irreversible de las proteínas. El porcentaje de degradación de las proteínas totales fue del $96.7 \%$ en relación con el control que se refiere a la leche hidrolizada tratada a $25{ }^{\circ} \mathrm{C}$. En la leche descremada, la degradación del $100 \%$ de las proteínas de suero y caseína se observó a $120{ }^{\circ} \mathrm{C}$ (Figura 3C y 3D).

El grado de desnaturalización proteica de la leche hidrolizada entera y descremada presentó una regresión exponencial con las diferentes temperaturas del tratamiento térmico:

$y=18.559^{e-1.808 x}$ (Leche hydrolizada entera)

$y=6.1911^{-1.037 x}$ (Leche hydrolizada descremada)

donde $Y$ representa el porcentaje de desnaturalización de proteínas de la leche.

\section{DISCUSIÓN}

Las proteínas de la leche sometidas a tratamiento térmico, dependiendo de las condiciones impuestas y el tiempo de calentamiento, pueden causar un cambio estructural de la proteína, comúnmente conocido como desnaturalización, que se acompaña del despliegue de proteínas y la exposición a grupos hidrófobos. Durante

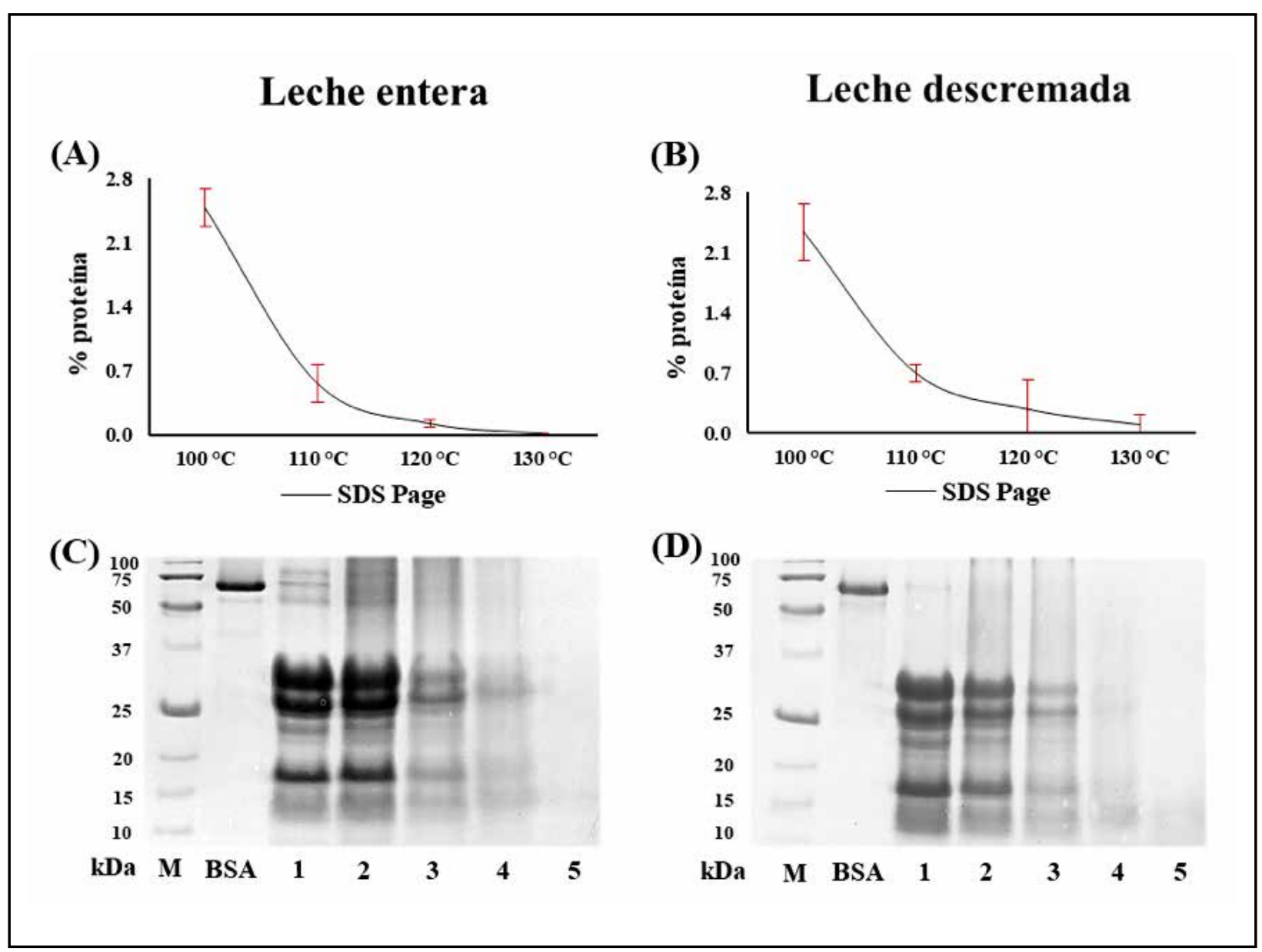

Figura 3: SDS-PAGE y proporción de proteínas de hidrolizado de leche entera y descremada en diferentes tratamientos térmicos. M: marcador de peso molecular, BSA: albúmina de suero bovino, línea $1: 25^{\circ} \mathrm{C}$ (control), líneas 2 a $5: 100{ }^{\circ} \mathrm{C}$, $110{ }^{\circ} \mathrm{C}, 120^{\circ} \mathrm{C}$ y $130{ }^{\circ} \mathrm{C}$. 
el tratamiento térmico, se forman pequeños agregados de beta-lactoglobulina que, según el aumento en la relación tiempo/temperatura, también aumentan la formación de agregados de beta-lactoglobulina desnaturalizados ${ }^{26}$. Cuando aumenta la temperatura y/o el tiempo de calentamiento, comienza la desnaturalización de la alfa-lactoalbúmina, que forma complejos con beta-lactoglobulina desnaturalizada, de modo que ambas proteínas desnaturalizadas se unen a la superficie de las micelas de caseína ${ }^{27}$.

La extensión del tratamiento con calor afecta el nivel de desnaturalización de la proteína de la leche, como se muestra en las figuras 3C y 3D. Las bandas de proteínas de la leche que se ven claramente cuando las muestras están a $25{ }^{\circ} \mathrm{C}$ desaparecen de la temperatura a $120^{\circ} \mathrm{C}$ o más durante un período de una hora. Esto es una indicación de que al menos algunas de las proteínas de la leche desnatada se desplegaron debido a la relación tiempo/temperatura, exponiendo grupos hidrófobos previamente ocultos y, por lo tanto, pudiendo formar agregados de altos pesos moleculares. Se han propuesto dos mecanismos para la interacción de proteínas de suero desnaturalizadas con calor con $\kappa$-caseína: el primero implica la disociación de -caseína de la micela de caseína en una etapa inicial de calentamiento, y posteriormente las proteínas de suero interactúan con la $\kappa$-caseína libre en la fase sérica. En el segundo mecanismo, cuando se agrega $\kappa$-caseína soluble a la leche desnatada, las proteínas de suero de leche menos descremadas se agregan a la superficie de la micela de caseína y cuando la $\kappa$-caseína soluble se calienta sin micelas de caseína en la fase de suero de leche o en condiciones modelo Los complejos se forman entre la $\kappa$-caseína y las proteínas de suero desnaturalizadas ${ }^{28,29}$.

Las proteínas del suero pueden ser utilizadas eficazmente por los seres humanos y proporcionan una cantidad considerable de aminoácidos esenciales para el crecimiento ${ }^{30}$. La desnaturalización de las proteínas del suero de leche se acompaña de la liberación de pequeños compuestos como el sulfato de hidrógeno y el metanitiol, que son compuestos muy sabrosos y causan sabores cocidos en la leche caliente ${ }^{31}$.

De acuerdo con los resultados, la intensidad de las reacciones de oscurecimiento (reacción de Maillard) en la leche hidrolizada entera y descremada aumentó gradualmente debido al aumento de la temperatura en función del aumento de temperatura, como se muestra en la figura 2. Montesdeoca ${ }^{32}$ se comprobó que la lactasa no incide sobre la variable carbohidratos. De igual forma, la variable energía no se ve influencia por la interacción del factor A (dosis de lactasa) y B (porcentaje de sacarosa). Cuellas e Wagne ${ }^{r 33}$ se comprobó que la única función de la lactasa es hidrolizar la lactosa en glucosa y galactosa. Los autores probaron una dosis de $6,9 \mathrm{~mL}$ de beta-galactosidasa en $1 \mathrm{~L}$ de leche y afirmaron que la glucosa resultante de la hidrólisis no afecta de manera significativa la concentración de este carbohidrato en el medio, pero sí hay un cambio estructural (hidrólisis de la lactosa) en dicho parámetro. De la misma forma, la energía variable no está influenciada por la enzima beta-galactosidasa. Pardo ${ }^{34}$ indica que una caloría es la medida de energía proveniente de los alimentos, de acuerdo con su composición de nutrientes y fuente de energía. Los carbohidratos y las proteínas proporcionan 4 $\mathrm{cal} / \mathrm{g}$, grasas $9 \mathrm{cal} / \mathrm{g}$, mostrando que no es posible ningún tipo de relación e incidencia de la beta-galactosidasa en la energía.

La reacción de Maillard es una Cascada compleja de reacciones, principalmente durante el calentamiento de los productos alimenticios, lo que produce cambios en la calidad de los alimentos, como el sabor y el color ${ }^{35,36}$. Esta reacción se subdivide en tres etapas: etapa inicial, etapa intermedia y etapa final. En la etapa inicial, los grupos amino y los azúcares reductores se condensan e inducen el comienzo de la reacción, como consecuencia de esta condensación existe la formación de bases de Schiff, un subproducto inestable ${ }^{37}$. Luego, la base de Schiff experimenta un reordenamiento secuencial, conocido como producto amadori (azúcar de aldosa) o producto de Heyns (azúcar de cetosa). Patel et al. ${ }^{38}$ declararon que el desarrollo del color en la reacción de Maillard aumenta con la temperatura, el tiempo de calentamiento y el tipo de azúcar reductor. Los resultados obtenidos en el experimento se corroboran con las afirmaciones de los autores mencionadas anteriormente, porque en la leche entera y desnatada el color aumentó gradualmente en función del aumento de temperatura, como se muestra en la figuras $2 \mathrm{C}$ y $2 \mathrm{D}$, respectivamente.

Dependiendo de los tipos de proteínas y azúcares que componen el alimento, el proceso produce resultados diferentes en cuanto al aspecto, color y sabor. Una de las razones para usar la lactosa hidrolizada, además de aumentar la dulzura y la solubilidad, es la formación de colores y sustancias aromáticas, debido a la reacción de Maillard. Fernández et al..$^{39}$ observaron que la leche en polvo deslizada presentó una coloración oscura en comparación con la leche en polvo tradicional. Este fenómeno es debido a la mayor disponibilidad de azúcares reductores en su composición, favoreciendo la reacción de Maillard.

La intensidad del color depende del tipo de alimento y la extensión de la reacción y puede resultar en cambios en la calidad del alimento, como el aroma, el sabor y el $\operatorname{color}^{40}$. Según Lyster ${ }^{41}$, la desnaturalización de $\beta$-lactoglobulina y $\alpha$-lactalbúmina $\left(78^{\circ} \mathrm{C}\right.$ y $117^{\circ} \mathrm{C}$ ) en la leche entera no es significativamente diferente de la leche descremada y no se ve afectada por tratamientos térmicos consecutivos a $78^{\circ} \mathrm{C}$ y $117^{\circ} \mathrm{C}$. La desnaturalización de las proteínas séricas y su asociación con micelas de caseína a través de reacciones intermoleculares entre los grupos $-\mathrm{SH} / \mathrm{S}-\mathrm{S}$ se producen durante el calentamiento de la leche ${ }^{42}$. Después de calentar a una temperatura de 75 a $100{ }^{\circ} \mathrm{C}$ durante hasta 60 minutos, la micela de caseína aumenta de tamaño debido a la cantidad de proteínas de suero desnaturalizadas que interactúan. Mientras que, durante el calentamiento a temperaturas que oscilan entre $75^{\circ} \mathrm{C}$ y $85^{\circ} \mathrm{C}$, la velocidad a la que las proteínas del suero interactúan con las micelas de caseína aumenta 
lentamente con el tiempo de calentamiento. Mientras que entre $90^{\circ} \mathrm{C}$ y $100^{\circ} \mathrm{C}$, la tasa de interacciones de la proteína del suero con las micelas de caseína es rápida ${ }^{43}$.

En varios productos lácteos como la leche en polvo, la leche y la leche esterilizada, la reacción de Maillard conduce a la pérdida de valor nutricional ${ }^{44}$. Según Naranjo et al. ${ }^{19}$, la temperatura es el factor más importante que debe controlarse para minimizar la pérdida del valor nutricional de los alimentos. Los productos lácteos son muy sensibles a la reacción de Maillard debido a su alto contenido de azúcares reductores y proteínas ricas en lisina. La leche hidrolizada es más propensa al deterioro de proteínas porque durante la hidrólisis de la lactosa se produce la liberación de monómeros de glucosa y galactosa que son más reactivos que el disacárido, participando más reactivamente en la reacción de Maillard ${ }^{19,45}$.

\section{CONCLUSIÓN}

El objetivo de este trabajo fue verificar el efecto de calentamiento en la desnaturalización de proteínas y la reacción de Maillard en leches hidrolizadas entera y descremada. Los resultados confirmaron que la temperatura del tratamiento de calentamiento tuvo efectos significativos sobre las proteínas de la leche desnaturalizada y con una combinación de proteína de suero y caseína. Con el aumento de la temperatura, aumentó el porcentaje de desnaturalización de la proteína del suero y el grado de combinación de la proteína del suero y la caseína. La degradación de la proteína se observó a $100{ }^{\circ} \mathrm{C}$ en $100 \%$ en leche entera y no descremada. El efecto de la temperatura en la variación de color entre las leches entera y descremada se debe probablemente a la protección en que los lípidos ejercen en la reacción de Maillard. Dependiendo del tipo de producto lácteo, es esencial para la industria adaptar las condiciones adecuadas de tratamiento térmico para mejorar la estabilidad de la proteína de la leche y reducir la pérdida nutricional.

\section{BIBLIOGRAFÍA}

1. Bailey RK, Fileti CP, Keith J, Tropez-Sims S, Price W, AllisonOttey SD. Lactose intolerance and health disparities among African Americans and Hispanic Americans: an updated consensus statement. J Natl Med Assoc 2013; 105(2): 112-127.

2. Carneiro A, Siqueira K. Conjuntura do mercado-lácteo. Boletim Eletrônico Mensal. Embrapa Gado de Leite-Folderes/ Folhetos/Cartilhas (INFOTECA-E) 2013; 6(46).

3. Bayoumi R, De Fanti S, Sazzini M, Giuliani C, Quagliariello A, Bortolini E, et al. Positive selection of lactase persistence among people of Southern Arabia. Am J Phys Anthropol 2016; 161(4): 676-684.

4. Zychar BC, Oliveira BA. Fatores Desencadeantes da Intolerância á Lactose: Metabolismo Enzimático, Diagnóstico e Tratamento. Atas de Cienc da Saúde 2017; 5(1): 35-46.

5. Mattar R, Mazo DFDC. Intolerância à lactose: mudança de paradigmas com a biologia molecular. Rev Assoc Med Bras 2010; 56(2): 230-236.
6. Rangel AHDN, Sales DC, Urbano SA, Galvão Júnior JGB, Andrade Neto JCD, Macedo CDS. Lactose intolerance and cow's milk protein allergy. Food Sci Technol (Campinas) 2016; 36(2): 179-187.

7. Saqib S, Akram A, Halim SA, Tassaduq R. Sources of $\beta$-galactosidase and its applications in food industry. Biotech 2017; 7(1): 79.

8. Lule V, Garg S, Tomar S, Khedkar C, Nalage D. Food intolerance: lactose intolerance. In: B Caballero, PM Finglas, F Toldrá (eds.) Encyclopedia of food and health. Academic Press, Oxford, UK, 2016; 43-48.

9. Roy I, Gupta MN. Lactose hydrolysis by Lactozym immobilized on cellulose beads in batch and fluidized bed modes. Process Biochem 2003; 39(3): 325-332.

10. Contreras-Calderón J, Guerra-Hernández E, García-Villanova $B$. Utility of some indicators related to the Maillard browning reaction during processing of infant formulas. Food Chem 2009; 114(4): 1265-1270.

11. Sato, N. Cresce lançamento de produtos sem lactose no Brasil. São Paulo: Mintel; Update in: 01/28/2016; accessed in: 10/19/2017. Available from: http://brasil.mintel.com/blog/ noticias-mercado-alimentos-bebidas/cresce-lancamento-deprodutos-sem-lactose-no-brasil.

12. Torres JKF, Stephani R, Tavares GM, Carvalho AF, Costa RGB, Schuck P, Perrone IT. Hidrólise da lactose e produção de leite em pó: Aspectos tecnológicos. Rev Inst Laticínios Cândido Tostes 2016; 71(2): 94-105.

13. Stanciuc N, Rapeanu G, Stanciu S. Quantitative evaluation of colour development in milk model systems during heat treatment: a kinetic study. Rom Biotechnol Lett 2010; 15(3): 5331-5341.

14. Laguerre JC, Pascale GW, David M, Evelyne O, Lamia A-A, Inès $B$-A. The impact of microwave heating of infant formula model on neo-formed contaminant formation, nutrient degradation and spore destruction. J food Eng 2011; 107(2): 208-213.

15. Van Lancker F, Adams A, De Kimpe N. Chemical modifications of peptides and their impact on food properties. Chem Ver 2011; 111(12): 7876-7903.

16. Mesías M, Seiquer I, Navarro MP. Consumption of highly processed foods: Effects on bioavailability and status of zinc and copper in adolescents. Food Res Int 2012; 45(1): 184-190.

17. Valero E, Villamiel M, Miralles B, Sanz J, Martınez-Castro I. Changes in flavour and volatile components during storage of whole and skimmed UHT milk. Food Chem 2001; 72(1): 51-58.

18. Messia M, Candigliota T, Marconi E. Assessment of quality and technological characterization of lactose-hydrolyzed milk. Food Chem 2007; 104(3): 910-917.

19. Naranjo GB, Gonzales ASP, Leiva GE, Malec LS. The kinetics of Maillard reaction in lactose-hydrolysed milk powder and related systems containing carbohydrate mixtures. Food Chem 2013; 141(4): 3790-3795.

20. Kato $Y$, Matsuda $T$, Kato $N$, Watanabe $K$, Nakamura $R$. Browning and insolubilization of ovalbumin by the Maillard reaction with some aldohexoses. I Agric Food Chem 1986; 34(2): 351-355.

21. Friedman M. Food browning and its prevention: an overview. J Agric Food Chem 1996a; 44(3): 631-653.

22. Friedman $M$. The impact of the Maillard reaction on the nutritional value of food proteins. In the Maillard reaction: consequences for the chemical and life sciences. Wiley and Sons 1996b; 43(1): 105-128.

23. Schamberger GP, Labuza TP. Effect of green tea flavonoids 
on Maillard browning in UHT milk. Food Sci Technol 2007; 40(8): 1410-1417.

24. Qian F, Sun J, Cao D, Tuo Y, Jiang S, Mu G. Experimental and Modelling Study of the Denaturation of Milk Protein by Heat Treatment. Korean J Food Sci Anim Resour 2017; 37(1): 44.

25. Grewal MK, Chandrapala J, Donkor O, Apostolopoulos $\checkmark$, Vasiljevic T. Electrophoretic characterization of protein interactions suggesting limited feasibility of accelerated shelf-life testing of ultra-high temperature milk. J Dairy Sci 2017; 100(1): 76-88.

26. Jang HD, Swaisgood HE. Disulfide bond formation between thermally denatured $\beta$-lactoglobulin and $\kappa$-casein in casein micelles. J Dairy Sci 1990; 73(4): 900-904.

27. Fox PLH. 2003. Milk Proteins: General and Historical Aspects. In: Fox, P. F., McSweeney, Paul L. H. (Eds.). Advanced Dairy Chemistry: Volume 1: Proteins, Parts A \& B. Third edition. New York - USA: Springer US; XXXVI, 1346.

28. Anema SG. Effect of temperature and rate of acidification on the rheological properties of acid skim milk gels. I Food Process Preserv 2008; 32(6): 1016-1033.

29. Donato L, Guyomarc'h F, Amiot S, Dalgleish DG. Formation of whey protein $/ \kappa$-casein complexes in heated milk: Preferential reaction of whey protein with $\kappa$-casein in the casein micelles. Int Dairy J 2007; 17(10): 1161-1167.

30. Hambraeus L, Lönnerdal B. Nutritional aspects of milk proteins. Advanced dairy chemistry-1 proteins: Springer, 2003; 605-645.

31. Al-Attabi Z, D'Arcy B, Deeth H. Volatile sulphur compounds in UHT milk. Crit Rev Food Sci Nutr 2009; 49(1): 28-47.

32. Montesdeoca R, Intriago R, Vera P, Benítez I. Efecto de la adición de lactasa y sacarosa en una bebida isotónica utilizando lactosuero. Rev Chil Nutr 2018; 45(4): 316-322.

33. Cuellas A, Wagner J. Production of energy drink from whey cheese. Inn Tec 2010; 5: 54-57.

34. Pardo C. Reflection on the energy balance. Alimentos hoy; 2013; 22: 15-19.
35. Newton AE, Fairbanks AJ, Golding M, Andrewes P, Gerrard JA. The role of the Maillard reaction in the formation of flavour compounds in dairy products-not only a deleterious reaction but also a rich source of flavour compounds. Food Funct 2012; 3(12): 1231-1241.

36. Demiate IM, Konkel FE, Pedroso RA. Avaliação da qualidade de amostras comerciais de doce de leite pastoso-composição química. Ciênc Tecnol Aliment 2001; 21(1): 1-7.

37. Shibao J, Bastos DHM. Produtos da reação de Maillard em alimentos: implicações para a saúde. Rev Nutr 2011; 24 (6): 895-904.

38. Patel KN, Modi R, Patel H, Aparnathi K. Browning, its Chemistry and Implications in Dairy Products: a Review. Indo-Am J Agric Vet Sci 2013; 1(1): 1-12.

39. Fernández E, Schebor C, Chirife J. Glass transition temperature of regular and lactose hydrolyzed milk powders. LWT - Food Sci Technol 2003; 36(5): 547-551.

40. Namiki M. Chemistry of Maillard reactions: recent studies on the browning reaction mechanism and the development of antioxidants and mutagens. Adv Food Nutr Res 1988; 32: 115-184.

41. Lyster RLJ. The denaturation of a-lactalbumin and $P$-lactoglobulin in heated milk. J Dairy Res 1970; 37: 233-243.

42. Considine T, Patel H, Anema S, Singh H, Creamer L. Interactions of milk proteins during heat and high hydrostatic pressure treatments-a review. Innov Food Sci Emerg Te 2007; 8(1): $1-23$.

43. Anema SG, Li Y. Association of denatured whey proteins with casein micelles in heated reconstituted skim milk and its effect on casein micelle size. J Dairy Res 2003; 70(1): 73-83.

44. Erbersdobler HF, Somoza V. Forty years of furosine-Forty years of using Maillard reaction products as indicators of the nutritional quality of foods. Mol Nutr Food Res 2007; 51(4): 423-430.

45. Ferrer E, Alegría A, Farré $R$, Abellán $P$, Romero F. Effects of thermal processing and storage on available lysine and furfural compounds contents of infant formulas. J Agric Food Chem 2000; 48(5): 1817-1822. 